\title{
МЕТОДОЛОГИЧЕСКИЕ ОСНОВЫ ПРОТИВОДЕЙСТВИЯ ГУМАНИТАРНЫМ ИНФОРМАЦИОННО-ПСИХОЛОГИЧЕСКИМ УГРОЗАМ СТУДЕНТАМ ВУЗОВ РОССИЙСКОЙ ФЕДЕРАЦИИ
}

\section{METHODOLOGICAL BASES OF COUNTERING THE HUMANITARIAN INFORMATION-PSYCHOLOGICAL THREATS TO STUDENTS OF UNIVERSITIES OF THE RUSSIAN FEDERATION}

\section{A. Evsiouk}

Summary: The author of the article substantiate the need to create departments of mediapsychology, subordinate to the ideas of developing students' protective mechanisms to counter information threats that entail risks of mental deformation. It is proved that potential threats turn into psychological risks only on the appropriate foundation - when there is a decrease in the level of awareness that occurs by activating the sensory-emotional reactions of a person to the detriment of the rationally conscious. According to the authors of the article, the rigidity of thinking, the external locus of control, low rates of self-attitude and imperfect mechanisms of psychological defense are the leading set of factors that does not allow individuals to counteract humanitarian information and psychological threats.

Keywords: informatization, information security, students, consciousness, mediapsychology, emotional-volitional sphere, conformity, manipulative influence.

\section{Актуальность}

$\Pi$ оследствия негативного влияния социальных сетей на сознание личности остаются недостаточно осознанными современной молодежью. Данный факт необходимо переосмыслить на уровне образовательных учреждений с целью формирования методологических основ разъяснительной работы, посвящённой информационно-психологическим угрозам среди студентов учебных заведений. В основу разработки новых профилактических мер, минимизирующих информационно-психологические риски необходимо положить тезис о том, что информационные потребности человека, его стремление к самоактуализации и самореализации в виртуальной среде, уже стали частью современного мира, однако, только сам человек создаёт благоприятные условия для удовлетворения данных потребностей либо в перспективном, либо в деструктивном направлении.

\author{
Евсюк Александр Владимирович \\ К.nсх.н., С.н.С., Военный университет Министерства \\ обороны Российской Федерации, Москва \\ avev2020@bk.ru
}

Аннотация: Автор статьи обосновывает необходимость создания кафедр медиапсихологии, подчиненных идеям развития у студентов защитных механизмов противодействия информационным угрозам, влекущим риски деформации психики. Обосновывается, что потенциальные угрозы превращаются в психологические риски только на соответствующем фундаменте - когда имеет место снижение уровня осознанности, происходящего путем активизации чувственно-эмоциональных реакций человека во вред рационально-осознанным. По мнению авторов статьи, ригидность мышления, экстернальный локус контроля, низкие показатели самоотношения и несовершенные механизмы психологической защиты - ведущий комплекс факторов, который не даёт личности противодействовать гуманитарным информационно-психологическим угрозам.

Ключевые слова: информатизация, информационная безопасность, студенты, сознание, медиапсихология, эмоционально-волевая сфера, конформность, манипулятивное воздействие.
Массовому сознанию молодёжи уже нанесены непоправимые морально - психологические травмы, связанные с тем, что глобальная информатизация всех сфер жизни произошла слишком быстро и общество не успело к ней адаптироваться. В связи с этим произошло падение ценности человеческой жизни, утрата ее смысла; прогрессирует цинизм, ценностный и правовой нигилизм, алчность, обесценивается институт брака и семьи; открытая пропаганда нетрадиционных ориентаций, наркотиков и т.д. проникает в сознание молодых людей по всем каналам восприятия. Человечество, несомненно, осознает глубину этих проблем, но намного меньше понимает, что необходимо делать, чтобы преодолеть последствия непрерывного формирования мировоззрения молодежи в деструктивном направлении.

При таких условиях, именно педагогам высшей школы, задействованным в воспитании креативно мыслящей молодежи в университетах страны, необходимо более глубоко погрузиться в мир психологии юношества, 
понять, что университетское образование подчинено единственной актуальной на сегодня и глобальной в перспективе цели преодоления многомерности негативного влияния информатизации, которая складывается из формирования собственных твёрдых жизнеутверждающих основ, намерений, речевых основ коммуникации, поведения, моральных принципов существования, организации своей воли и усилий на преодоление требований времени, наряду с сохранением исторической памяти своего народа и классического понимания роли гендера.

Цель данной статьи: исследовать возможности и перспективы объединения методологических основ противодействия гуманитарным информационно-психологическим угрозам студентам ВУЗов Российской Федерации в новую единую дисциплину «медиапсихология».

Сегодня, осознавая всю проблемность вопросов повышения качества осознанности студентов в информационном пространстве, университеты должны сконцентрировать силы и возможности гуманитарных наук, чтобы пойти на рискованный эксперимент создания кафедр медиапсихологии, подчиненных идеям развития у студентов, прежде всего, защитных механизмов противодействия информационным угрозам, влекущим риски деформации психики.

В современных условиях информационные угрозы превращаются в психологические риски только на соответствующем фундаменте - когда имеет место снижение уровня осознанности, происходящего путем активизации чувственно-эмоциональных реакций человека во вред рационально-осознанным. Если психический мир находится на стадии становления, что свойственно именно студенческому возрасту, то информационные угрозы перерастают в формирование соответствующих аттитьюдов, антиценностей, деструктивных стратегий поведения, которые в дальнейшем эволюционируют и приводят к девиантному поведению и формированию психических расстройств.

Результаты эмпирического исследования авторов Л.Г. Дмитриева, Д.В. Хамзина подтвердили очень важную гипотезу, что «у студентов, которые являются активными пользователями социальных сетей, проявление черствости более выражено, чем у студентов, которые реже пользуются социальными сетями. Студенты - неактивные пользователи социальных сетей характеризуются большей чуткостью и более глубоким пониманием других людей» [2]. Ежедневно проникая в сознание студентов и воздействуя на него через личное бессознательное, используя незрелость психических процессов молодых людей, проявляющуюся в повышенной конформности, масс-медиа внушают, вводят в сознание молодёжи некую псевдореальность.
Именно поэтому, с целью обеспечения информационной безопасности студентов на уровне государства и системы образования должны осуществляться определенные защитные меры, которые необходимо базировать на следующих методологических подходах:

1. Регулирование информационных потоков и связей, в частности их количественное ограничение. Использование данной группы мер на личном уровне связано с отказом студентов от использования информации или каналов ее распространения (например, отказ от просмотра рекламной продукции) в случае невозможности проверки ее достоверности. На уровне образовательной организации необходимо создание кафедры медиапсихологии, реализующей подготовку студентов к избирательной обработке сетевой информации.

2. Целенаправленное информирование студентов, в частности, распространение просветительской информации. Сюда стоит отнести организацию информационных потоков, направленных на предотвращение и нейтрализацию воздействий определенных информационных факторов, которые могут иметь негативные последствия. На личном уровне это проявляется в инициативном поиске дополнительной информации из различных источников и в организации ее поступления другими каналами. На уровне образовательной организации рекомендуется создание сетевых сообществ под курацией преподавателей-психологов, рапространяющих качественных контент. Возможно создание специализированного Ютубканала для аудиально-визуального донесения опасностей информационного пространства.

3. Применение способов, методов и средств регулярного предоставления социально важной информации в ежедневном общении на занятиях по всем дисциплинам. Данная группа включает разнообразные формы регулярного предоставления социально значимой информации, в частности, через систему образования, подготовки и переподготовки кадров, распространения духовных и культурных ценностей, поддержания традиций, морально-этических норм.

4. Формирование механизмов коллективной защиты от негативных информационно-психологических воздействий. Прежде всего, эти меры связаны с организацией коллективной защиты, основанной на механизмах идентификации студентов с определенными социальными общностями. Для этого могут применяться различные приемы и средства, в частности формирование положительного морально-психологического климата в студенческих коллективах, актуализация чувства принадлежности студентов к будущей интеллектуальной элите общества, от которой зависит вектор развития всего государства. 
5. Воспитание индивидуальной способности студентов к информационно-психологическому сопротивлению. Данная группа мероприятий направлена на приобретение студентами практического опыта безопасного информационно-коммуникационного взаимодействия (например, обучение с использованием специализированных форм психологической подготовки) для формирования индивидуального психологического механизма самозащиты. Вместе с тем, одним из путей обеспечения информационно-психологической безопасности студентов выступает организация безопасного личностного информационного пространства как в университете, так и в семье. Организовать безопасное информационное пространство возможно путем реализации средств и мероприятий по информационной безопасности, среди которых: правовые, технические и программные, воспитательные и организационные, моральные и этические.

А) Правовые средства - это специальные законы и другие нормативные акты, правила, процедуры и мероприятия, направленные на обеспечение безопасности личностной информационной среды на законодательной и правовой основе, для реализации единой государственной политики в сфере защиты от информационных материалов, наносящих вред здоровью и психике.

Б) Технические и программные мероприятия предусматривают использование различного рода аппаратного и программного обеспечения для предотвращения нанесения материального и морального вреда студенту (программы Родительского контроля, сетевых средств защиты данных).

В) Воспитательные мероприятия - формирование у подрастающего поколения культуры психологической безопасности, ответственности за совершенные действия в информационном пространстве, воспитание и укрепление духовно-нравственных ценностей, патриотизма, готовности родителей и педагогов к принятию личностной позиции и уважения к его самостоятельности.

Г) Организационные меры - это регламентация информационной деятельности студентов, контроль за использованием сетевых сервисов и сообществ, что исключает или ослабляет нанесение вреда личной информационной среде молодого гражданина страны.

Д) Моральные и этические меры включают в себя соблюдение студентами при осуществлении информационной деятельности норм и правил поведения в обществе, а также сетевой культуры и этики, формирующейся с распро- странением информационных технологий в современном обществе.

6. Рекомендуем ввести обязательную комплексную дисциплину, лежащую на стыке педагогики, психологии и социологии, которая будет составлена с учётом необходимости формирования комплекса умений и навыков студентов, способствующих успешному противостоянию манипуляциям: критическое мышление (способность выстроить барьер критичности), умение избегать и игнорировать источники манипуляции, медитативные техники ауторелаксации, которые помогут избежать перенапряжения (именно при повышенной утомляемости манипуляции легко осуществимы), а также целостное укрепление «цензуры» психики и развитие здорового чувства юмора.

Важно доводить до сознания студентов то, что:

- информационный ресурс стал основным средством психологического влияния;

- происходит рост количества каналов влияния и усложняются возможности их перекрытия или блокирования;

- почти отсутствуют политические и географические ограничения в распространении информации, что влечет невозможность централизованного контроля;

- социальные сети, которые активно расширяются, становятся каналом для предоставления искаженной или угрожающей информации;

- происходит уменьшение способности пользователей абстрагироваться от ненужной информации, поскольку она проникает сквозь эмоциональное восприятие и влияет на бессознательное мышление;

- формируется зависимость пользователей информационного пространства от получения необходимой информации и стираются границы между реальными событиями и фактами и виртуальной реальностью и системой образов;

- разработаны специальные эффективные методики осуществления информационно-психологического воздействия для направления мнения молодёжи в выгодном для акторов медиасреды, зачастую деструктивном, направлении.

Вторая группа методологических основ противодействия информационным стрессам: работа с психологическими структурами студентов, которые делают их уязвимой категорией для манипуляций и деформации сознания. В таблице 1 продемонстрировано соотношение внешних источников информационной среды, которые могут стать факторами опасности, с индивидуальными факторами информационно-психологического риска. 
Таблица 1.

Соотношение внешних источников информационной среды, которые могут стать факторами опасности с факторами информационно-психологического риска

\begin{tabular}{|c|c|}
\hline $\begin{array}{l}\text { Внешние источники информационной среды, которые могут стать фактора- } \\
\text { ми опасности }\end{array}$ & Факторы информационно-психологического риска \\
\hline $\begin{array}{l}\text { Психологические установки общества (соответствие кодов сообщений } \\
\text { паттернам восприятия, наличие или отсутствие дефицита времени и } \\
\text { перегрузки оперативной памяти человека, организация информационных } \\
\text { потоков в соответствии с алгоритмами деятельности и т.д.) }\end{array}$ & $\begin{array}{l}\text { Незрелость личности, выражающаяся в неспособности к самостоятельному } \\
\text { осознанному выбору информации, релевантной своим убеждениям, прин- } \\
\text { ципам, потребностям и планам. Сюда же относится отсутствие целей при } \\
\text { поиске информации (несформулированный поисковый запрос), что способ- } \\
\text { ствует «поглощению» первого же попадающегося контента. }\end{array}$ \\
\hline $\begin{array}{l}\text { Наличие в информационных потоках специфических элементов, целена- } \\
\text { правленно изменяющих психофизиологическое состояние больших масс } \\
\text { людей или лиц, принимающих важные для социума решения }\end{array}$ & $\begin{array}{l}\text { Установки личности на конформизм, подражательство, на готовность к вос- } \\
\text { приятию манипулятивных информационных воздействий }\end{array}$ \\
\hline $\begin{array}{l}\text { Наличие в информационной среде (или «примешивание» к информаци- } \\
\text { онным потокам) модифицированных физических носителей информации, } \\
\text { воздействующих непосредственно на физиологические носители (свето- } \\
\text { вые, звуковые, электромагнитные воздействия) }\end{array}$ & $\begin{array}{l}\text { Измененное в негативную сторону функциональное состояние головного } \\
\text { мозга и психики }\end{array}$ \\
\hline $\begin{array}{l}\text { Блокирование на неосознаваемом уровне свободы волеизъявления } \\
\text { человека, искусственное привитие ему синдрома зависимости; утрате } \\
\text { способности к политической, культурной, нравственной самоидентифика- } \\
\text { ции человека }\end{array}$ & $\begin{array}{l}\text { Состояние социума, способствующее повышенной внушаемости, массовому } \\
\text { «заражению» идеями, призывами, исходящими от харизматической лично- } \\
\text { сти, и вызываемое психоэмоциональным стрессом, фрустрацией, тревож- } \\
\text { ностью }\end{array}$ \\
\hline $\begin{array}{l}\text { Наполнение сознания человека определёнными стереотипами, ограничи- } \\
\text { вающими суждения установками, искажению образа мира, ценностных } \\
\text { ориентаций личности и невозможностью личностного осмысления по- } \\
\text { ступающей информации, }\end{array}$ & Поверхностное мышление вследствие недостаточной начитанности \\
\hline
\end{tabular}

В данном аспекте можно детализировать ряд основных моментов.

1. Среди студентов ВУЗов РФ есть множество легко управляемых индивидов, которые склонны легко воспринимать манипуляторные воздействия информационного пространства, что актуализирует проблему изучения психологических основ такой уязвимости, а также эффективных психологических стратегий противодействия данным видам воздействий.

2. Студенты зачастую проявляют проекцию как механизм психологической защиты, что свидетельствует о наличии тенденции к приписыванию другим определенных чувств, желаний. Преобладание таких механизмов психологического противостояния информационным стрессам как отрицание, вытеснение, реактивное образование - позволяет с помощью соответствующих технологий информационно-психологического воздействия подсознательно направлять людей к «необходимым» мыслям, настроениям, которые в дальнейшем укрепляются в обществе и приводят к определённым действиям.

3. Педагогам важно уметь выделять такие психические качества студентов, которые важны для исследования повышенной подверженности информационным угрозам. Это качества как интел- лектуальные, так и личностные, а именно: ригидность мышления, экстернальный локус контроля, низкие показатели самоотношения и несовершенные механизмы психологической защиты.

Поскольку людям с ригидным типом мышления легче внушить те или иные социальные стереотипы, то именно это определенным образом облегчает работу масс-медиа для культивирования среди них «соответствующих» установок, ценностей, стереотипов. В силу собственной инертности, такие личности часто поддаются влиянию окружения, господствующие мысли других им кажутся своими собственными, и как следствие - они становятся главными объектами манипуляторного воздействия.

4. По нашему мнению, при совокупности таких качеств, как низкие самоуверенность, самосознание и самоответственность, а также высокой склонности к самообвинениям, - личность не имеет четко сформированной собственной позиции, она нерешительна, склонна поддаваться негативным влияниям извне. Прежде всего такие характеристики указывают на тот факт, что определенная категория студенчества не проявляет «близости к себе», им не свойственна личностная твёрдая позиция, для них характерно отсутствие стремления управлять собственной жизнью, вследствие чего 
они становятся своеобразным «пластилином», который принимает формы более организованных окружающих структур.

Проведенное эмпирическое исследование Е.Ю. Кольчик, направленное на «выявление особенностей социально-психологической безопасности студентов с различной степенью выраженности параноидальных черт» [3], дало возможность говорить о том, что для реализации угроз всегда должны быть предпосылки в виде патологических акцентуаций, черт, девиаций.

5. Значительное доминирование экстернального локуса контроля указывает на склонность студентов к приписыванию ответственности за свою жизнь внешнему окружению, что проявляется в таких чертах как неуверенность в своих возможностях, тревожность, подозрительность, конформность. Чем выше уровень ригидности мышления, тем ниже уровень интернальности, поэтому студенты с такими характеристиками ищут авторитарное влияние, что в целом неплохо, при обретении разумного руководства (например, со стороны субъектов образовательной среды) и приобретает резко негативный контекст при попадании под влияние деструктивной личности.

6. В исследовании авторов Самойлова В.В. и др. приводится следующий психологический портрет интернет-зависимых студентов: «характеризуются такими показателями эмоционально-волевой сферы их личности, как высокие уровни личностной тревожности, агрессивности и враждебности. При повышении уровня интернет-зависимости отмечается последующее увеличение данных характеристик. Кроме того, для интернет-зависимых студентов свойственны низкие показатели стрессоустойчивости, самооценки и уверенности в себе» [4].

Перспективы дальнейших исследований. По-нашему мнению, дальнейших разработок требует установление причинно-следственных связей в контексте предшествования патологических черт характера, формирующихся при длительно протекающей интернет-зависимости). Также важно провести исследование на большой выборке студентов с целью установления параметров интернет-зависимости и специфических черт её отличия от загруженности работой за компьютером.

Несмотря на вышесказанное, бесспорно, что информация является основным стратегическим ресурсом нового информационного общества, однако, наряду с очевидными преимуществами, это, в первую очередь, актуализирует вопросы социального и психологического комфорта личности в информационно-образовательной среде студентов и предопределяет важность изучения понятия информационная безопасность именно в контексте влияния на сознание потребителей информации.

На сегодня информация не является абстрактным понятием, так как представляет ценность на уровне политическом, экономическом, репутационном, личностном. Кроме того, обновляются формы и процессы ее производства, хранения, повышаются риски потери, недобросовестного приобретения, владения, использования с недобрыми намерениями и тому подобное. Всё это приводит к новым стрессовым факторам, которым подвержены студенты ежедневно.

Целесообразность совершенствования понятийнокатегориального аппарата в аспекте исследуемой темы. Как верно отмечено в статье С.М. Герцен, «выражения «неправильное использование Интернета» или «гигиена Интернета» пока не имеют общепринятого определения, хотя в отечественной литературе широко распространен термин интернет-зависимость» [1]. По-нашему мнению, формирование соответственного понятийного аппарата в данной сфере должно лечь в основу внедрения нового предмета в ВУЗах - медиапсихологии.

Всё вышесказанное обусловливает необходимость исследования студентами с помощью педагогов высших школ, понятия информационной безопасности как соизмеримой и прогрессивной отрасли коммуникационных технологий и социальных коммуникаций в целом, который нуждается в новом осмыслении их понятийного аппарата. Мы предлагаем рассматривать понятие «информационной безопасности» не только в смысле защищенности информации и информационной инфраструктуры от случайных и преднамеренных воздействий естественного или искусственного характера, которые наносят существенный вред субъектам информационных отношений, то есть пользователям и владельцам информации. Изучение понятия следует начать на глобальном уровне с кардинально иного ракурса, в частности, в контексте медиапсихологической безопасности, поскольку мы осознаем, что объектами такого нежелательного информационного воздействия могут быть как информационно-технические системы, так и массовое или индивидуальное сознание, психика человека.

Информационную безопасность следует исследовать в контексте достижений таких отраслей научных знаний, как медиапсихология и теория массовых коммуникаций, так как современное информационное пространство вышло далеко за границы средств массовой информации, охватив всю сферу межличностного общения, образования, производства.

\section{Выводы}

1. Сегодня, осознавая всю проблемность вопросов повышения качества осознанности студентов в 
информационном пространстве, университеты должны сконцентрировать силы и возможности гуманитарных наук, чтобы пойти на эксперимент по созданию кафедр медиапсихологии, подчиненных идеям развития у студентов, прежде всего, защитных механизмов противодействия информационным угрозам, влекущим риски деформации психики.

2. Главные негативные тенденции в исследуемой сфере: информационный ресурс стал основным средством психологического влияния; происходит рост количества каналов влияния и усложняются возможности их перекрытия или блокирования; почти отсутствуют политические и географические ограничения в распространении информации, что влечет невозможность централизованного контроля; социальные сети, которые активно расширяются, становятся каналом для предоставления искаженной или угрожающей информации; происходит уменьшение способности пользователей абстрагироваться от ненужной информации, поскольку она проникает сквозь эмоциональное восприятие и влияет на бессознательное мышление; формируется зависимость пользователей информационного пространства от получения необходимой информации и стираются границы между реальными событиями и фактами и виртуальной реальностью и системой образов.

3. В современных условиях информационные угрозы превращаются в психологические риски только на соответствующем фундаменте - когда имеет место снижение уровня осознанности, происходящего путем активизации чувственно-эмоциональных реакций человека во вред рациональноосознанным.

4. Если психический мир находится на стадии становления, что свойственно именно студенческому возрасту, то информационные угрозы перерастают в формирование соответствующих аттитьюдов, антиценностей, деструктивных стратегий поведения, которые в дальнейшем эволюционируют и приводят к девиантному поведению и формированию психических расстройств.

\section{ЛИТЕРАТУРА}

1. Герцен С.М. Влияние социальных сетей на студентов ВУЗов // Высшее образование сегодня. 2018. №7. URL: https://cyberleninka.ru/article/n/vliyaniesotsialnyh-setey-na-studentov-vuzov (дата обращения: 12.07.2020).

2. Дмитриева Л.Г., Хамзина Д.В. Особенности проявления эмпатии у студентов - пользователей социальных сетей // Вестник Московского государственного лингвистического университета. Образование и педагогические науки. 2020. №1 (834). URL: https://cyberleninka.ru/article/n/osobennosti-proyavleniyaempatii-u-studentov-polzovateley-sotsialnyh-setey (дата обращения: 12.07.2020).

3. Кольчик Е.Ю. Социально-психологическая безопасность у лиц с параноидальными чертами // Мир науки. Педагогика и психология. 2019. №6. URL: https://cyberleninka.ru/article/n/sotsialno-psihologicheskaya-bezopasnost-u-lits-s-paranoidalnymi-chertami (дата обращения: 12.07.2020).

4. Самойлова В.В. Психологический портрет интернет-зависимого студента // Теоретическая и практическая психология в современных условиях. - 2019. C. 138-143.

(с) Евсюк Александр Владимирович (avev2020@bk.ru).

Журнал «Современная наука: актуальные проблемы теории и практики» 